\title{
HUMANIS
}

Journal of Arts and Humanities

p-ISSN: 2528-5076, e-ISSN: 2302-920X

Accreditation Sinta-4, SK No: 23/E/KPT/2019

Vol 26.1 February 2022: 34-43

\section{Cooperative Principle Appliance on Daily Conversation of The Verneuil}

\author{
I Gede Agus Sastrawan, Sajarwa \\ Universitas Gadjah Mada, Yogyakarta, DIY. Yogyakarta \\ Correspondence email: gede.agus.s@mail.ugm.ac.id, sajarwa@ugm.ac.id
}

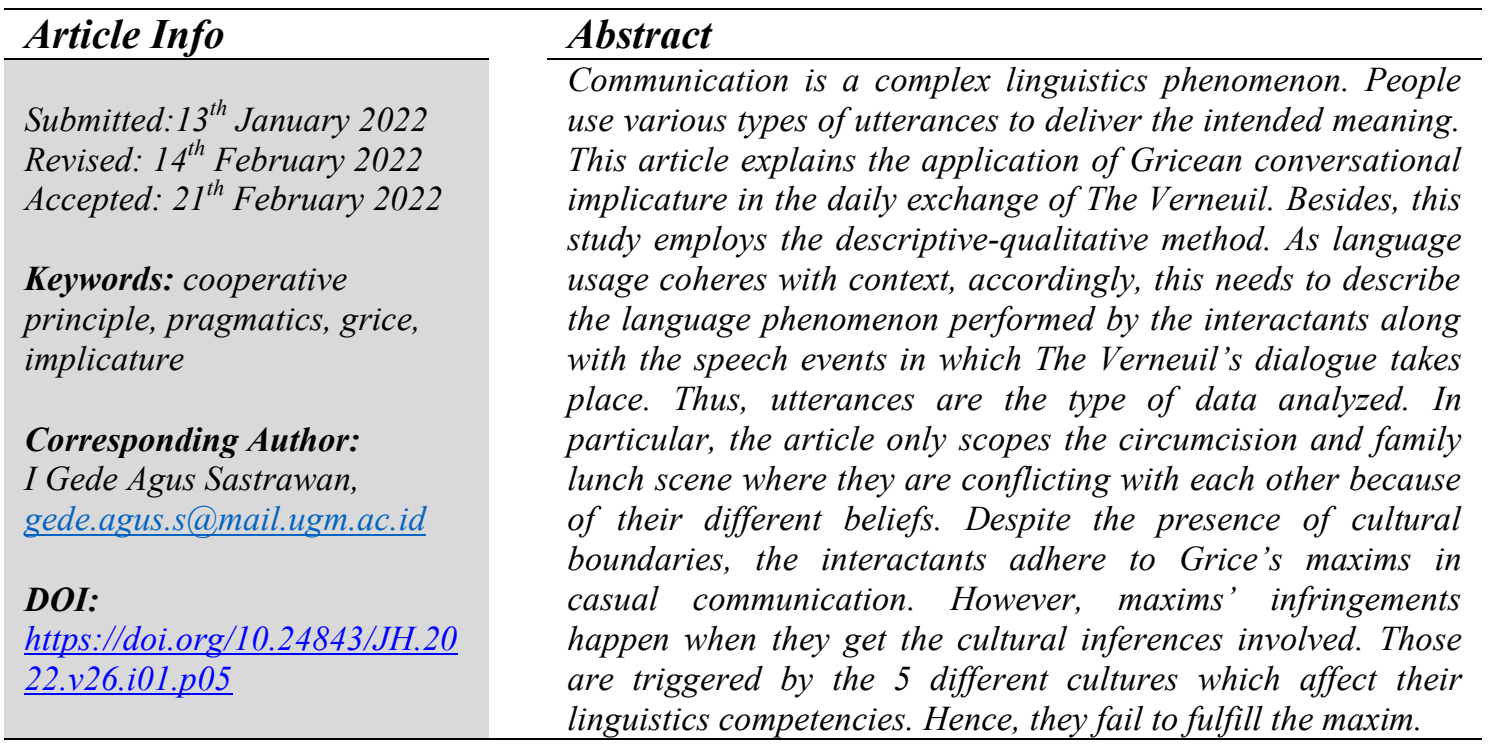

\section{INTRODUCTION}

People live in cultural complexity. A community consists of many different cultures and so, the way people speak will be different: the accent, cultural presupposition, and other identities may be carried along with the speech. Consequently, it leads the interactants to join intercultural communication (Kotthoff \& Spencer-Oatey, 2007, p. 1). This phenomenon normally happens in multicultural communities as it crucially understands the background of the interactants. Thus, cultural differences may affect the conversation between two, or more, participants. Then, why does this happen? In the general case, Tannen (2005, p. 4) said that people need to communicate because they are afraid of being self-isolated.

Practically, communication across cultures is seen in France and, at the same time, issues arise between French native speakers and immigrants from francophone countries as Wijana (1996, p. 45) interprets communication as a social activity. The problems do not concern the most to the grammatical interest, but it is more likely how the speaker delivers his concept or idea to the addressee.

However, could it possibly be done properly? To reach this hypothesis, Grice shows in his work, a volume called Studies in the way of words (1989), that communication will run properly when participants follow, what he named later 
on as, the Cooperative Principles (henceforth: CP). This includes 4 maxims that relate one to another. But somehow, we will find that the speaker is not willingly following the principles for some reason and may perform onedominant-maxim thereof. Hence, this drives the speaker's intention to deliberately violate one's maxim or more.

At various indications which are probably to happen in a conversation, this research tries to analyze: (1) if the interactants adhere to the Gricean $\mathrm{CP}$; conversely, (2) in case the interactants are not conserving the $\mathrm{CP}$, what maxims are likely to violate? Participants may perform different maxim exploitation break one (or more) maxim(s). Here, it is important to understand what is beyond the verbal activity in which an utterance relies on its context. Eventually, this will lead the interlocutor to infer the utterance properly.

There are so many researchers fascinated with Gricean Cooperative Principles since its publicly released in 1975. He worked on so many essays compiled, so-called, Studies in the way of words, and Cooperative Principles can be found in the essay of Logic and Conversation. His background as a philosopher of language gives a philosophical touch on his work that shows the very basic rational consideration of the speaker-meaning.

Following the previous paragraphs, many researchers use the Gricean theoretical framework to see the speaker's intention - the implicature of the utterance. Thus, conversation exchange is the most relatable area to see one of the pragmatic phenomena while it applies variably, as follows:

Thakur (2016) analyses how participants generate pragmatic inferences on fictional discourse with the use of CP. In general, they stick to Gricean's maxims but often violate and flout them because of social emotions (e.g. attitude, tension, conflict, etc.) and socio-cultural factors (e.g. politeness, tact, power, taboos, etc.). Also, Abdi et al., (2010) are interested in CP of discourse community and genres. It sounds more interesting to collaborate social phenomenon with language activity in a writing style. However, this was firstly discovered in 1986, said Swales through his journal "Reflections on the concept of discourse community" (2016). Their research reviewed 6 disciplines of 36 recent articles in 2007 which ended up on the relationship of metadiscourse strategies and CP's categories.

In addition, Murray (2009) applied $\mathrm{CP}$ for pedagogical purposes therefore learners will accurately understand the speaker's intended meaning. Linear with Murray's research, Zhou (2009) is also analyzing CP for improving Chinese students' English communicative competence. On the other hand, Virgin and Utami (2017) only talked about the violation in Hitam Putih Talkshow. Despite 4 existing maxims, they come to conclude that the speaker and hearer tended to violate the maxim of relevance. At the same focus, these two researchers explain the maxim exploitation in Comedy (Niclas, 2013; Puspasari \& Ariyanti, 2019).

If these researches adhere to CP conceptualization, Davies (2007) technically leaves a questionable problem to Gricean CP of cooperation term which leads us into a peripheral distinction of sentence-meaning and speaker-meaning. Moreover, he mentions that Grice aims to find the logic of conversation and so, rationality is the most important in his work. Not only Davies, Agnes (2013) raises the application of $\mathrm{CP}$ for Indonesian then concluded that the maxim of Quality and Manner are deliberately disobeyed. 
All the researches mentioned above have their own speciality. However, the present research shows the Gricean CP appliance in France, with a touch of socio-cultural perspective. Accordingly, this article also mentions how the intercultural communication lasts between native and immigrants interactants adherence to $\mathrm{CP}$ or even tend to violate one maxim.

The image is well represented in the film Qu'est-ce qu'on a fait au bon dieu? (de Chauveron, 2014) or 'Serial Bad Weddings' in English. It tells about 4 daughters of Verneuil's family (Isabelle, Odile, Segolène, and Laure) married with 4 immigrants 'population issue de l'immigration' (Rachid, David, Chao, and Charles). Based on their daily conversation, the interactants presuppose "what is behind the utterance" and "how that affects the language productivity". For further analysis, we could consider the below conversation.

(1) Laure : "Ah je suis désolée, Charles. Le problème c'est que t'arrive après les trois autres. Tu comprends?"

'I'm sorry Charles... The problem is that you come after the 3 others. You understand?'

Charles : "Oui, oui ..." 'Yeah'

Laure : "Sois patient ... Il faut que je les prépare au choc"

'Be patient. I need to prepare them to this shock'

Charles : "C'est moi le choc?" 'Am-I the shock?'

Based on the above conversation, Charles's utterance pragmatically implicates something beyond his speech. Before stepping forward, I should mention the conversation context. In the movie, Charles is described as an African, Black and so, he is not an ideal son-in-law to the Verneuil family. This is understood when Claude told André Charles's father - that he wanted a French, Whiteman, and European son-inlaw. On the other hand, André wishes to have a Congolese, Blackman, and African daughter-in-law. Here, it is clear that the contrast between these two families is totally conflicted.

Globally agreed by pragmatist, language as a medium of talk exchange is a social phenomenon shaped by numerous linguistics and non-linguistics aspects, e.g. social and situational factors (Sajarwa, 2021, p. 140; Wierzbicka, 2003, p. 1). This is beyond the linguistics activity that explains background knowledge of an utterance. If Laure knows that her parents are against her relationship with Charles, then she needs to hold the Christmas invitation on because of Charles's social and racial identity. Also, this leads us to understand her speech "Il faut que je les prépare au choc" violating the quantity maxim but keeping it relevant by following the maxim of relevance - this event mentiones what Grice (1989, p. 30) called as clash: violating one maxim for adhering one maxim. The use of au choc determines the unfamiliar marriage mixte 'mixed marriage' is for The Verneuil as French, European. An utterance may have pragmatic inferences when it coheres with the context and linear to its felicity conditions, otherwise, the utterance is barely a part of pragmatic but a grammaticalized sentence. Considering the above supposition, pragmatics becomes the most important competency to achieve communicative goals.

\section{METHOD AND THEORY}

This research reviews the daily conversation of The Verneuil in the film "Qu'est-ce qu'on a fait au bon dieu" 
('Serial Bad Weddings' in English) by Philipe de Chauveron in 2014, a movie that represents social issues between French and Immigrants. The family present in the film is considered complex because it consists of 5 different cultures. Hence, their everyday exchange is uniquely varied, and how they conserve communication is the key point to understand.

As for data collection, the film shows diverse types of utterances. The data collection stages involve: (1) borrowing the $\mathrm{CD}$ from IFI-LIP Yogyakarta; then (2) watching the film; and (3) specifying particular scene as 'circumcision' and 'the family lunch'; the last step is (4) identifying and interpreting utterances from the collected conversation.

Following the above data collection, this study employs the descriptivequalitative method. As language usage coheres with context, accordingly, this needs to describe the language phenomenon performed by the interactants along with the speech events in which The Verneuil's dialogue takes place. Regarding the utterances collected, the analysis starts with the pragmatics approach to see the relation of language and context as a whole to define the implicature. Secondly, utterances are classified into Gricean's CP to reach maxims' adherence and exploitation categories.

At this point, uttering something is, sometimes, doing something. This shows that words have illocutionary force, a term introduced by Austin (1962) to complete his theoretical framework socalled Speech Acts which is also a branch of Pragmatics. Hence, what Pragmatics is? To understand that conceptualization, Pragmatics is a set of, I would say, competencies as Parker \& Riley (2014, p. 28) describe that it talks about the relation of language and context.
Pragmatics is a study of the ability of language users to pair the sentences with the contexts in which they would be appropriate (Levinson, 1983, p. 24). These two things are important before knowing the implication of an utterance. And so, the process of inferring the implicature is the study of Pragmatics. Thus, Maingueneu (2015, p. 18) shortly explained it as the correlation of signs and its users. He (ibid:22) continues that this is not about "true or false" but "réussi ou non" or Austin (1962, p. 54) prefers to say it as 'happy or unhappy' situation.

An utterance may introduce multiple inferences by default which depends on the interactants' ability and their linguistics experience in real-life usage. Thus, conversational implicature is established to make conversation effective. This is one of the most salient theories that came from Grice where he started with the notion of Implicature. By this term, implicature means the process of inferring an utterance (Grice, 1989, pp. 24-25; Levinson, 1983, p. 97). To complete his essay, Grice (1989, p. 24) adds two terms concerning his concept: imply for 'implying' and implicatum for 'what is implied'. In order to infer properly, implicature depends on the mutual knowledge raised in the conversation between the interactants and the capability of the interlocutor interpreting the implicature and so, Levinson (1983, p. 97) extends that an utterance may understand more than one pragmatic inference. Eventually, this kind of linguistic experience makes conversation difficult to establish.

Initiating a conversation, the interactants need to work cooperatively. Hence, Grice pushes a theoretical framework known as Cooperative Principles to make communication between the speaker and the interlocutor effective and efficient, or simply, we could say that they should make the 
exchange cooperatively by giving information as required, true, relevant, and clear. Thus, the interlocutor can infer the implication properly and lead them to achieve the communicative goal.

Following the above idea, Gricean $\mathrm{CP}$ provides 4 maxims to follow: quantity, quality, relevance, and manner (Grice, 1989, pp. 26-27). But, this does not mean the interactants willingly adhere to the concept of $\mathrm{CP}$ in every situation. Some conditions make a participant in talk exchange accidentally or intentionally infringe the Gricean $\mathrm{CP}$ (ibid, p. 33). As a consequence, Grice (ibid) adds four terms to finalize his idea, such as: (1) violate: intend to mislead; (2) flout: speaker wished to be uncooperative; (3) opt-out: unwilling to be cooperative (e.g.: I cannot say more; my lips are sealed); and (4) clash: a participant may be unable to fulfil one maxim without violating another maxim.

\section{RESULTS AND DISCUSSION}

People need to communicate their idea to their social circle. A speaker delivers the concept of speech which contains social and cultural norms, or even, beliefs conveying that this is the best way to express the idea. Also, the way people speak based on their linguistic experience determines word choices and expression. Speech is a human activity that varies without assignable limit as we pass from social group to social group because it is a purely historical heritage of the group, the product of long-continued social usage (Sapir, 1921, p. 5)

Verneuil's family consists of 5 different cultures i.e. French Catholic, Algerian Muslim, Hispanic Jews, Han Chinese, and Black West African. These dissimilarities provision a difficult to set up a conversation between them. Grice believes that communication would run properly when the speaker and interlocutor follow the Cooperative
Principles. Not only that, Levinson (1983, p. 101) mentions Gricean's theory of implicature is a broad pragmatics approach and is the key to achieving the intended message, or a non-conventional meaning. Pursuing Grice, there are 4 maxims and their violations.

\section{Cooperative Principle Observed by The Interactants}

\section{Maxim of Quantity}

For commencing, Grice (1989, pp. 26-27) proposes the maxim of quantity. In this term, the speaker should contribute as required and do not surpass the information needed than is required, or make it less informative. Performing adequate contributions can help the interlocutor to infer the intended meaning properly. Therefore, too much information or uninformative expression in talk exchange will present a violation or maxim infringement.

(2)

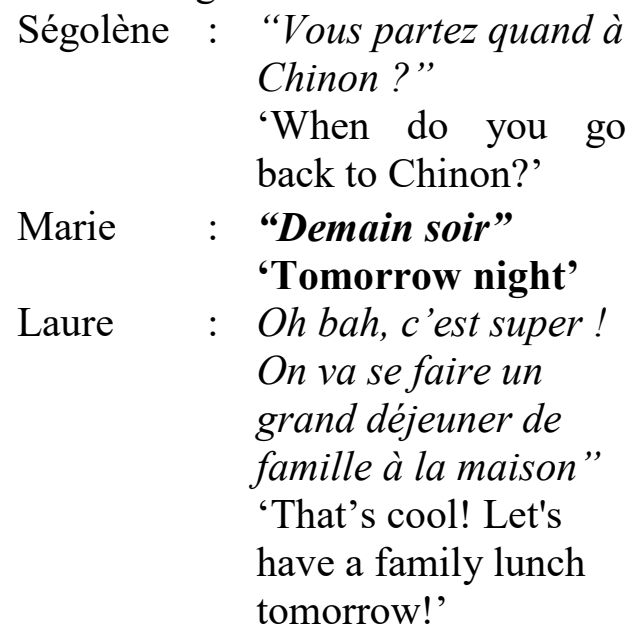

Based on the above conversation, the participants seem to adhere to the Gricean CP. The communication runs perfectly without any misunderstandings. The speaker intends to know 'when their parents would go back to Chinon' and she uses quand 'when' as the interrogative markers. If the addressee tries to be cooperative, she will indicate the time e.g. date or time. Thus, Marie's response as 'tomorrow's evening' makes 
the conversation effective. Otherwise, imagine if Marie responds '?tomorrow evening, maybe', the above conversation will struggle Ségolène because of the word 'maybe'. It may raise another question further.

\section{Maxim of Quality}

It is not only the amount of information but also the truthness of the speech. Grice (1989, p. 27) strict the speaker to provide information that is true or do not say something which lacks adequate evidence. If one believes the utterance is not true, it will mislead the hearer and unwillingly to participate cooperatively.

(3) Marie

$\begin{array}{ll} & \text { !' } \\ \text { Rachid } & \text { 'Hello everyone!' } \\ & \text { "Bonjour Marie, } \\ & \text { bonjour Claude. Vous } \\ \text { avez fait un bon } & \text { voyage? } \\ & \text { 'Hello Marie, hello } \\ & \text { Claude. How was your } \\ & \text { vacation?' } \\ \text { Claude : 'Très bien, merci } & \\ & \text { 'Great. Thanks' }\end{array}$

A successful conversation is not only considered by adhering to the quantity's maxim but also the quality maxim. In the above talk exchange, Rachid believes that he presents true evidence in his utterance. Naturally, as it is true, the interlocutor cooperatively responds to the speaker's question and qualifies Rachid's utterance as fact-based information by Claude's response "Très bien, merci". Implicitly, Claude confirms the truth of the speaker's utterance.

?'Hello Marie, hello Claude, I know you have been on vacation. Thus, I wanted to know further, how was your vacation?'

There are lots of possibilities in a conversation, but what is actually implied? It depends on the shared knowledge between the interactants. Consider the raised trial utterance, Rachid may say as above but he will violate the maxim of quantity by making his utterance too long. To make it effectively concise while the speaker knew the fact that Marie and Claude were on vacation which is also the mutual knowledge between the interactants, he deleted the italic part. Hence, he follows the maxim of quantity and quality at the same time and so, by virtue of his adherence to the maxims, he conserves the communication.

\section{Maxim of Relevance}

The quantity and quality of information are important but not sufficient. The speaker has to make his/her contribution relevant to the talk exchange (Grice, 1989, p. 27). Stick with the conversation's topic will build a communicative exchange.

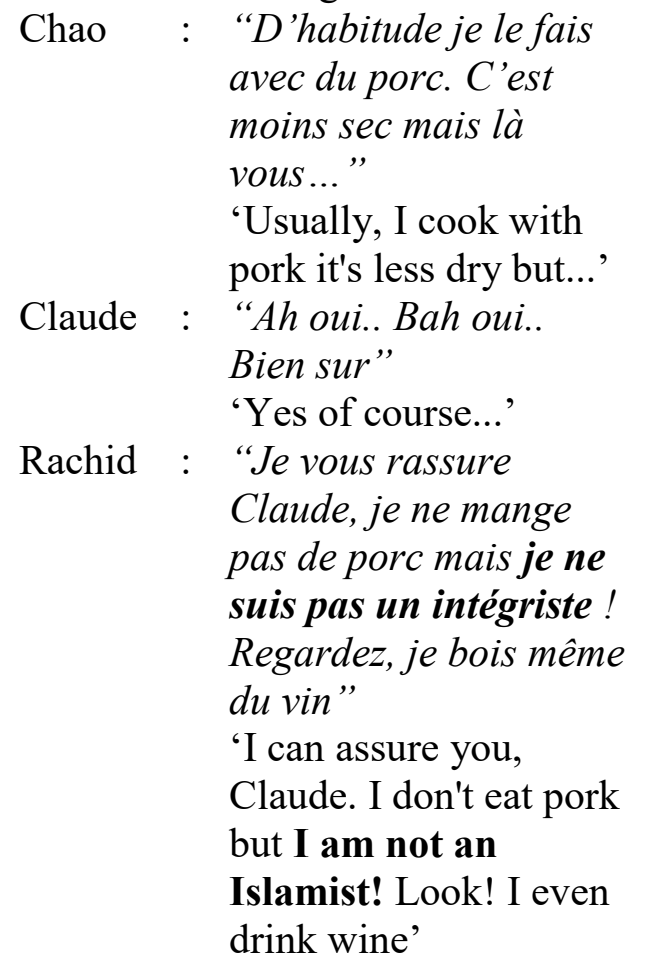

The Gricean theoretical framework gives us the acquaintance of rationality in conversation. Following the above data, all the family members were invited by Chao to have lunch in his house. He is Chinese and so, he is making Chinese 
dishes. For the first exchange, he mentions that he usually cooks porkbased dishes but he changed it into turkey to make Rachid and David comfortable. But, his speech does not make the interlocutor happy and Rachid seems to imply the speech satirically. To keep on the path, he responds '... I am not an Islamist...'. If we cannot find out what is behind the speech, Rachid's utterance is considered irrelevant to the speech event.

\section{Maxim of Manner}

In the fourth maxim, Grice (1989, p. 27) mentions that the speaker has to make his/her contribution clear, brief, orderly, avoid obscurity and ambiguity. Applying these sub-maxims will take the particular attention of the interlocutor.

(5) Chao : "Tu veux dire quoi par là? Le Chinois est fourbe?"

'What do you mean? Chinese are deceitful?'

David : "Pas du tout... Je dis juste... que le Chinois ne fait aucun effort pour aller dans les autres. J'ai pas raison $? "$

'No I'm just saying Chinese make no effort to approach others! Right?'

Claude : “Joker"

'Joker'

When they are having lunch together, they talk about Benjamin's David's son - circumcision as a Jews compared to Rachid circumcision at the age of 6 . Yet, it turns into a racial issue when Chao interrupts them because David and Rachid keep arguing with each other. Then, the above conversation happened. At this point, the communication satisfies the interactants. It ends up with Claude's utterance 'Joker' and follows the sub-maxim of Manner, be brief. It means that he does not want to join the conflict between David and Chao.

\section{?'I don't know if that is true. I have no idea if Chinese people have no effort to communicate with others. I remain neutral'}

In the same situation, he will violate the maxim if he utters the above speech. Describing what is in mind is making the utterance not effective and efficient compared to 'Joker'. This possible example seems unusual. Hence, making it simple but clear can attract particular attention from the addressee instead of saying a complex paraphrase as above.

\section{Maxims Infringement in The Verneuil}

All four maxims that we have discussed are not always being observed by the interactants. They may violate the maxims for purposes and the addressee can not take them for granted. If the speaker is unwilling to be uncooperative, she/he may mislead the addressee (Cutting, 2002, p. 36; Grice, 1989, p. 30). There are various motifs behind the unwillingness to explain why one exploits maxim(s).

\section{Maxim of Quantity Violation}

In this part, one may violate the maxim of quantity by giving too much information or less than is required by means misleading the addressee (Grice, 1989, p. 33). The speaker shows this violation when she or he does not want to work cooperatively in a talk exchange. It may be caused by an uninteresting topic or conflict between the interactants.
(6) Marie
"Tu es sublime. Ça y'est vous lui avez choisi le prénom?"
'No you look radiant. Sublime! Did you chose a name?'
Isabelle : “Non, on n'a pas encore décidé maman. On hésite 
entre Antoine, Lucas, ou ..."

'No we haven't decided yet. We're hesitating between Antoine, Lucas or ...'

Rachid : "Mahmoud" 'Mahmoud'

Claude : "Mahmoud?" 'Mahmoud'

Rachid : "Ouais, j'aime bien Mahmoud. Et vous, vous préférez lequel alors?"

'Yeah I like

Mahmoud. What about you?'

Claude : "J-j-j. J'aime beaucoup les trois.

Enfin, j'avoue que j'ai une petite préférence pour Lucas et Antoine" 'I, I would say, all of them are nice... I probably prefer Lucas and Antoine tho...'

Marie : "Bah, oui. Mahmoud ce n'est pas facile à porter quand même. Ça sonne un peu Mammouth, non ?"

'Me too... Mahmoud it's not an easy name... It sounds like mammoth!'

Isabelle is pregnant and so, her mother if she has chosen a name or not. It looks normal at first until Rachid interrupts by suggesting a name as "Mahmoud". This is shocking Marie and Claude thereof. Rachid's utterance mentions what is implied and they suppose an Islamic cultural inference that is not so French. Eventually, Claude and Marie's response is contradictory and they prefer French names as they live in France. Thus, Rachid's utterance violated the maxim of quantity because of less information involved. On the other hand, Marie and Claude also violated this maxim as they put too much information to show their refusal.

\section{Maxim of Manner Violation}

One may exploit this maxim when the speaker mentions the ambiguity or obscurity (Grice, 1989, p. 36). Then, it leads to confusing the addressee because of incompetence to interpret what is implied. In this case, the speaker intends to violate the maxim when cultural inferences get involved in the utterance because she/he needs to explain more about the culture. However, the extended paraphrase made the utterances look odd to the interlocutor. The speaker has to consider the person with who is she/he talking with. Thus, he may observe the maxim and properly runs the communication.

\begin{tabular}{|c|c|}
\hline Chao & $\begin{array}{l}\text { “Ah, c'est une bonne } \\
\text { idée. Je vous ferai une } \\
\text { spécialité de mon } \\
\text { pays. Dimsum de } \\
\text { chiens bouillis à la } \\
\text { vapeur" } \\
\text { 'Great idea! I will } \\
\text { cook a specialty from } \\
\text { my country. A } \\
\text { steamed boiled dog } \\
\text { Dim Zum!' }\end{array}$ \\
\hline $\mathrm{C}$ & $\begin{array}{l}\text { "Ah ..?" } \\
\text { 'Ah ..?' }\end{array}$ \\
\hline
\end{tabular}

This is a type of exploitation found in the film. The speaker feels that he has to mention in advance what kind of dishes he is about to make for his parents-in-law. Yet, Chao's utterance contains cultural inference of Chinese. Hence, the interlocutor receives bizarre background knowledge compared to the French typical dishes. At this point, he also lost adequate referent to understand the speaker's utterance.

In-depth contextual detail, when Chao knows that his parents-in-law will 
go back to Chinon tomorrow evening (see: 2nd data), he wants to cook typical Chinese food. Nevertheless, he ends up confusing Claude by referring "...Dimsum de chiens bouillis à la vapeur". Consequently, he violates the maxim of manner sub-maxim 'avoid ambiguity' because the cultural inference is not properly understood by the addressee unless he speaks to Chinese. As French-European, Claude is not comfortable with the fact that he was invited to have a dog meat lunch. Supposing that Chao understands who he is speaking with, he has to keep it brief as 'Dimsum'. It will decrease the confusion probability.

\section{CONCLUSION}

The Verneuil consists of many different cultures, but, in a nutshell, they can operate the conversation cooperatively by following the Gricean maxim. This phenomenon has a high possibility to happen with a common convention that leads to conversational implicature satisfaction. Once an utterance to be seen as unusual to the other participants, the speaker may fail to fulfill one (or more) maxim(s). This concludes that the violation happens when an utterance mostly implied cultural inferences e.g. Claude as French prefers typical European names; but Rachid prefers Mahmoud as he is a Muslim; furthermore, Chao explains a bizarre conceptualization of a dish he wants to serve to his parents-in-law. These cultural inferences make the speakers fail to fulfill the maxim. Thus, they ended up violating the maxim and the interlocutor stressed with the inferences present in the utterance.

There are many perspectives to reach the empirical study of how the interactants suit the conversation to achieve communicative goals. This research is giving a pragmatic view of how intended meaning can be understood by the addressee through Gricean's conversational implicature. Furthermore, this type of data also can be studied by using conversation analysis in the sociolinguistics approach, language acquisitions (French L2) by immigrants in France, or subtitle translation. Besides, this may be studied from various disciplines out of linguistics major e.g. communication, anthropology, etc.

\section{ACKNOWLEDGEMENT}

Finally, this article has been finished. I was stuck at first considering the best approach to analyze the collected data. However, Monsieur Jarwa gave me a lot of advice and I would like to thank him for supervising me during the research.

\section{REFERENCES}

Abdi, R., Rizi, M. T., \& Tavakoli, M. (2010). The cooperative principle in discourse communities and genres: A framework for the use of metadiscourse. Journal of Pragmatics, 42(6), 1669-1679. https://doi.org/10.1016/j.pragma.20 09.11 .001

Austin, J. L. (1962). How to Do Things with Words. Clarendon Press.

Cutting, J. (2002). Pragmatics and Discourse-A Resource Book for Students. Routledge.

Davies, B. L. (2007). Grice's Cooperative Principle: Meaning and rationality. Journal of Pragmatics, 39(12), 2308-2331. https://doi.org/10.1016/j.pragma.20 07.09.002

Grice, H. P. (1989). Logic and Conversation. In Studies in the way of words. Harvard University Press.

Herawati, A. (2013). The Cooperative Principle: Is Grice's Theory Suitable to Indonesian Language 
Culture? Lingua Cultura, 7(1), 4348.

https://doi.org/10.21512/lc.v7i1.41 7

Kotthoff, H., \& Spencer-Oatey, H. (Eds.). (2007). Handbook of intercultural communication. Mouton de Gruyter.

Levinson, S. C. (1983). Pragmatics. Cambridge University Press.

Maingueneau, D. (2015). Manuel de linguistique pour les textes littéraires. Armand Colin.

Murray, N. (2009). Pragmatics, awareness raising, and the Cooperative Principle. ELT Journal, 64(3), 293-301. https://doi.org/10.1093/elt/ccp056

Niclas, A. (2013). Flouting the maxims in comedy. 34.

Parker, F., \& Riley, K. (2014). Linguistics for Non-Linguistics. Pearson Education South Asia Pte Ltd.

Puspasari, M. A., \& Ariyanti, L. (2019). Flouting Maxims in Creating Humor: A Comparison Study Between Indonesian and American Stand Up Comedy. 13, 14.

Sajarwa. (2021). Swear Words in French: Analysis of Social Class and Gender. Humanus, 20(2), 139-152. https://doi.org/10.24036/humanus.v 20i2.111969

Swales, J. M. (2016). Reflections on the concept of discourse community. ASp, 69, 7-19. https://doi.org/10.4000/asp.4774
Tannen, D. (2005). Conversational style: Analyzing talk among friends. Oxford University Press.

Thakur, V. S. (2016). Cooperative Principle Of Conversations in Vikram Seth's A Suitable Boy: A Socio-Pragmatic Assessment Of Inferential Chains Of Interpretation. International Journal of Education, 9(1), 24. https://doi.org/10.17509/ije.v9i1.37 14

Virgin, J. A., \& Utami, C. P. (2017). Dominant Maxim violations in 'Behind the Lawyer Profession' of Hitam Putih Talk Show. Proceedings of the Ninth International Conference on Applied Linguistics (CONAPLIN 9), 82. https://doi.org/10.2991/conaplin16.2017 .40

Wierzbicka, A. (2003). Cross-cultural pragmatics: The semantics of human interaction (2. ed). Mouton de Gruyter.

Wijana, I. D. P. (1996). Dasar-Dasar Pragmatik (1st ed.). Andi Offset.

Zhou, M. (2009). Cooperative Principle in Oral English Teaching. International Education Studies, 2(3). https://doi.org/10.5539/ies.v2n3p42 